\title{
Quem disse que Matemática não é brincadeira? Geometria, jogos digitais e ludicidade no ciclo da alfabetização
}

DOI 10.23864/cpp-v2-n1-159

Denília Andrade Teixeira dos Santos

\section{Resumo}

O presente artigo traz um relato de experiência em uma turma de alfabetização da rede pública, cujo planejamento tinha como objetivo consolidar habilidades referentes ao estudo de Geometria, sem perder de vista as capacidades da alfabetização e letramento em Língua Portuguesa. As capacidades foram trabalhadas por meio de sequências didáticas que contemplassem as metas de trabalho a serem alcançadas com a turma, dentre as quais se destaca desenvolvimento da leitura, escrita, produção de texto e Geometria. A necessidade de promover um trabalho interdisciplinar, rompendo com áreas de conhecimentos distantes umas das outras, com conteúdos estanques e pouco significativos para os estudantes, propiciou momentos de intenso deleite e aprendizagens múltiplas por meio de interlocução entre as áreas de conhecimento. A conexão estabelecida entre as diversas áreas de conhecimento teve como elo a linguagem e a tecnologia, por meio da utilização de atividades e recursos didático-pedagógicos lúdicos, com vistas a favorecer o desenvolvimento das crianças como sujeitos ativos no processo ensino-aprendizagem.

Palavras-chaves: Alfabetização matemática. Geometria. Tecnologia. Ludicidade. 


\section{Contexto dos desafios da matemática para a unidocência}

No início do primeiro semestre de 2015, durante a aula da disciplina "Tecnologias Aplicadas à Educação Matemática”, do curso de Especialização em Educação Matemática ofertado pelo Instituto Federal de Educação/Ouro Preto, os docentes anunciaram que um dos instrumentos de avaliação da disciplina seria a implementação de um plano de aula que visasse o uso de uma tecnologia digital durante as aulas de Matemática, nas respectivas turmas de atuação dos cursistas.

A partir desse anúncio, quedei-me pensativa, sem ter certeza de qual instrumento deveria empregar, pois, apesar de conhecer o Geogebra não o considerava o recurso mais eficaz para o trabalho com estudantes em seu segundo ano de educação escolarizada no Ensino Fundamental, turma de minha atuação naquele momento, em uma escola pública no município de Belo Horizonte/MG.

Julguei que, se decidisse pelo trabalho com o Geogebra, seria necessária melhor instrumentalização de minha parte para que seu uso com os estudantes pudesse ser efetivado, embora não o considerasse de fácil manipulação para estudantes com faixa etária de sete anos, com os quais atuava naquele momento.

Não posso deixar de ressaltar que minha formação é em Pedagogia e, por isso, necessitaria estudar a temática proposta com mais afinco, visto que o professor pedagogo, formado para atuar nos anos iniciais do Ensino Fundamental, não encontra em sua formação as especificidades técnicas da disciplina Matemática. Por isso, deveria buscar um recurso tecnológico que atendesse tanto aos interesses dos estudantes quanto aos meus objetivos didático-pedagógicos.

Assim, o desafio estava posto: ensinar Matemática usando um recurso tecnológico, preferencialmente digital, levando em consideração as necessidades e interesses da infância no ciclo da alfabetização.

A partir dos estudos a respeito da tecnologia digital, Sette (2013) explica que sua nomenclatura surge a partir das tecnologias oriundas dos recursos computacionais. Com o advento da tecnologia, a pesquisadora aponta a necessidade de, como instituição educacional, a escola se adaptar para o trabalho com a mesma, visto que:

Pesquisas mostram que as tecnologias digitais, nas escolas, mergulham os estudantes numa atmosfera contínua de criação e numa cultura de inovação, capaz de torná-los protagonistas do seu próprio destino. Elas oferecem uma enorme diversidade de informações e permitem interatividade e colaboração, sendo uma poderosa ferramenta para mudar os papeis, atualmente desempenhados por professores e alunos, em sala de aula. Nessa situação, o aluno tende a ganhar autonomia e o papel do professor é de orientador. (SETTE, 2013, p.42). 
Levando tal afirmação em consideração, sem perder de vista o estudante, como um dos protagonistas desse processo, a tecnologia escolhida para efetivação do trabalho foi o Geoplano. Fortuitamente este recurso foi apresentado por um grupo de colegas do curso de Especialização em Educação Matemática, visando o trabalho com Geometria e o cálculo de área de figuras geométricas. Na proposta de aula apresentada pelo grupo, o recurso trazido pelo grupo apresentava-se nas opções material concreto e digital e, desta forma, atenderia a necessidade pedagógica e o interesse educativo de meu público, levando em consideração os objetivos de aprendizagem elencados.

Concomitante ao curso de especialização, estava atuando como orientadora de estudos no Pacto Nacional pela Idade Certa (PNAIC) e os debates sobre a alfabetização matemática estavam permeando as rodas de conversa de docentes na Rede Municipal de Belo Horizonte.

Nos encontros com as docentes cursistas do PNAIC debatíamos sobre da necessidade de os docentes pedagogos buscarem aprofundar nos conhecimentos acerca do ensino e da aprendizagem da Geometria.

Devido aos desafios já expostos, busquei elaborar um plano de aula objetivando consolidar conhecimentos que contemplassem a aprendizagem da Geometria como conteúdo da Matemática. Devido à necessidade de aprofundarmos seus conceitos na fase de alfabetização, torna-se relevante o uso de materiais concretos para manipulação, de forma que os estudantes possam construir seu conhecimento a partir de experiências que o levem à reflexão.

Ao escolher a Geometria como conteúdo para exploração em Matemática, levava em consideração as conversas com os cursistas do PNAIC e minha própria experiência, já que é comum entre docentes que atuam na alfabetização, a preocupação com a alfabetização em Língua Portuguesa e em segundo plano ficam relegados os conteúdos da Matemática. Nesse compasso, a Geometria passa despercebida e somente ganha visibilidade ao final do ano letivo, quando já não há mais tanto tempo para seu ensino com a qualidade que se faz necessária para a consolidação de habilidades que se tornam pré-requisitos para outros conteúdos matemáticos a posteriori.

Ao estudar o conteúdo para trabalhar em sala de aula, busquei embasar-me em estudiosos e pesquisadores da Matemática que versam sobre a aprendizagem infantil, a ludicidade e a alfabetização Matemática, tais como: Sarquis (2010), Constance Kamii (1986), Smole e Diniz (2007), Danyluk (1991). Ao tratar da alfabetização e letramento em Língua Portuguesa, busquei como base teórica, Magda Soares (2003), Sônia Krammer (2010) e Cagliari (1999). Ausubel (1982) traz como contribuição para meu planejamento o conceito de 'aprendizagem significativa'. Em Dolz e Schenewuly (2004) busco a compreensão de sequência didática, tendo os gêneros textuis como ponto de partida. Como diretriz curricular, utilizei os 
Parâmetros Curriculares Nacionais (PCN) de Matemática e Língua Portuguesa (BRASIL, 1997) e as Proposições Curriculares da Rede Municipal de Belo Horizonte (BELO HORIZONTE, 2010) e os cadernos elaborados para o PNAIC (BRASIL, 2014).

\title{
O Plano de Aula
}

Para elaborar o planejamento das aulas recorri às Diretrizes Curriculares da Rede Municipal de Belo Horizonte (2010) e elenquei, no caderno de Matemática, as seguintes habilidades a serem trabalhadas com a turma de 27 estudantes do $2^{\circ}$ ano do $1^{\circ}$ ciclo do Ensino Fundamental:

\begin{abstract}
Observar, descrever e representar figuras geométricas; Identificar semelhanças e diferenças entre poliedros e não-poliedros; Identificar semelhanças e diferenças entre não-poliedros (cone, esfera, cilindro...); Identificar semelhanças e diferenças entre poliedros (cubo, prisma, pirâmide...); Identificar semelhanças e diferenças entre figuras tridimensionais e bidimensionais (cubo e quadrado, paralelepípedo e retângulo, pirâmides e triângulos, esferas e círculos); Identificar semelhanças e diferenças entre figuras planas mais comuns; Reconhecer e classificar nãopoliedros, poliedros, polígonos; Identificar e conceituar elementos de figuras geométricas como faces, arestas e vértices; Identificar simetria em elementos da natureza, construções humanas e figuras geométricas; Identificar diferentes planificações de alguns poliedros; Identificar propriedades a partir da composição e da decomposição de figuras geométricas. (BELO HORIZONTE, 2010, p.32-33).
\end{abstract}

Comumente, fazemos uma roda de conversa com os estudantes no ciclo da alfabetização, no início das aulas para estabelecimento da rotina do dia, expormos os planos de estudos, colhermos suas impressões e sugestões para enriquecimento, bem como passamos a conhecer seus conceitos e conhecimentos prévios a respeito do tema principal e dos assuntos que serão abordados.

Para o processo de alfabetização, o estabelecimento de rotina torna-se imprescindível, visto que, por meio desta, inteiramos os estudantes acerca dos acontecimentos do dia e oportunizamos a participação dos mesmos na elaboração das atividades, de forma que estes possam sentir-se protagonistas das atividades escolares.

Então, em uma roda de conversa, expus a eles meu plano de curso sobre a Geometria, dizendo-lhes o que e como faríamos para desenvolver as atividades propostas, em aproximadamente 40 aulas, que seriam trabalhadas ao longo dos meses de julho, agosto e setembro.

Em seguida, disse-lhes dos recursos que utilizaríamos e os listamos em ordem alfabética, para aproveitarmos a oportunidade de trabalhar atividades voltadas para a alfabetização, pois conforme afirma Batista (2005), vivemos em uma sociedade grafocêntrica, 
na qual o uso da escrita é valorizado e de extrema importância para a participação dos cidadãos na vida social:

Trabalhar os conhecimentos e capacidades envolvidos na compreensão dos usos e funções sociais da escrita implica, em primeiro lugar, trazer para a sala de aula e disponibilizar, para observação e manuseio pelos alunos, muitos textos, pertencentes a gêneros diversificados, presentes em diferentes suportes. Mas implica também, ao lado disso, orientar a exploração desses materiais, valorizando os conhecimentos prévios do aluno, possibilitando a ele deduções e descobertas, explicitando informações desconhecidas. (BATISTA, 2005, p.31).

A lista ficou bem extensa, visto ser composta por barbantes e embalagens de produtos industrializados, passando pelo Geoplano físico e virtual e o jogo "Os blocos" (site Leo AKIO, 2015) até finalizar com os sólidos geométricos e o Tangram. Os estudantes participaram da elaboração ora listando os recursos, ora organizando em ordem alfabética.

Baseado em uma proposta sociointeracionista, teríamos as aulas expositivas dialogadas, bem como atividades lúdicas diversas, visando estimular os estudantes à participação e demonstração de seus conhecimentos prévios.

No planejamento estava previsto a participação de estudantes de outros ciclos em algumas aulas, além de familiares dos estudantes da turma quando da confecção das pipas na culminância do trabalho.

Acordamos, ainda, que o ponto de partida seria o livro do autor Max Luccado "Você é meu" (LUCCADO, 2004), pois, a concepção de alfabetizar-letrando que adoto em meu fazer didático-pedagógico, parte do princípio de que os gêneros textuais são instrumentos imprescindíveis no processo de alfabetização e que potencializam a interdisciplinaridade. Por isso, recorreríamos a outros livros literários ao longo do trabalho, dentre estes “Clact...clact...clact...” (IACOCCA, 1986) e "Nunca conte com ratinhos" (D’ANGELO, 2011).

No planejamento, estabeleceram-se capacidades que seriam trabalhadas em Língua Portuguesa e em Matemática, a partir de sequências didáticas, que contemplassem os objetivos iniciais e as metas de trabalho a serem alcançadas com a turma, levando em consideração o desenvolvimento da leitura, escrita, produção de texto e consolidação de conceitos da Geometria.

Adoto a concepção de Dolz e Schenewuly (2004) como base teórica para o trabalho com sequência didática, que afirmam serem estas um conjunto de atividades articuladas que são planejadas com a intenção de atingir determinado objetivo didático e são organizadas em torno de um gênero textual oral ou escrito ou de um conteúdo específico, podendo envolver diferentes componentes curriculares.

A escolha do modelo da sequência a ser utilizada está relacionada, portanto, aos objetivos que eu, como docente, pretendia alcançar diante das necessidades dos alunos, 
elencando princípios didáticos de valorização dos conhecimentos prévios dos estudantes. Desta forma, o ensino é compreendido como forma de promover a reflexão, com ênfase na explicitação verbal e na interação/sistematização dos saberes, por meio de atividades diversificadas, desafiadoras e com a possibilidade de progressão, colocando a criança como sujeito ativo na construção do seu conhecimento.

Dentre as atividades propostas para abordagem do conteúdo, constavam a planificação das embalagens, montagem de sólidos geométricos, reconhecimento de figuras a partir de sua planificação, montagem de sólidos com palitos e massa de modelagem, aula expositiva sobre planos e sólidos, suas semelhanças e diferenças, a importância da Geometria.

O Tangram seria um dos recursos para enriquecer as aulas, sendo trabalhada sua história e o exame de suas peças para a montagem de modelos, construção de figuras planas a partir de outras (exemplo: construir um quadrado com triângulos...), exploração das vértices, arestas e faces de um sólido.

Para não perder de vista a alfabetização em da Língua Portuguesa, por meio da elaboração de bilhetes e convites para a família, seriam abordadas as seguintes capacidades:

Conhecer, utilizar e valorizar os modos de produção e de circulação da escrita na sociedade. Conhecer usos e funções sociais da escrita. Conhecer usos da escrita na cultura escolar. Desenvolver capacidades necessárias para o uso da escrita no contexto escolar: saber usar objetos de escrita presentes na cultura escolar; desenvolver capacidades específicas para escrever. (BATISTA, 2005, p. 16).

O livro didático de Matemática adotado pelo escola para atendimento aos estudantes do ciclo da alfabetização, A conquista da Matemática (Giovanni Júnior, 2011), seria mais um recurso didático, auxiliando na consolidação das atividades tanto lúdicas quando formais.

Expus aos estudantes o objetivo de tantas atividades, quando fiz a leitura para eles da lista de atividades que eu havia planejado. A reação da turma foi um alarido geral devido à longa lista. Embora os estudantes não tivessem certeza do que se tratava de fato, esclareci a eles que a lista poderia sofrer modificações a qualquer momento e que todos eles poderiam sugerir mudanças. Além disso, disse-lhes que teríamos muito tempo para executarmos todo o plano, pois a finalidade deste seria uma aprendizagem que pudesse ser importante para toda sua vida. Mas, deixei para o final da conversa a informação que, certamente, mexeria com todos: aulas de Matemática na sala de informática.

Contei-lhes, finalmente, que teríamos jogos com a Geometria no computador ao longo da execução de nosso projeto de trabalho. A reação, como previsto, foi eufórica e comentários múltiplos, sendo seguidos por as sugestões diversas.

Após inúmeras deliberações e registros em meu caderno, acordamos que o encerramento do projeto seria uma oficina de confecção de pipas e, em seguida, iríamos para o campo de futebol, localizado ao lado da escola, para brincarmos. 
Como alguns estudantes afirmaram que haviam aprendido confeccionar seus papagaios com avós, tios, primos e pais, decidimos, em parceria com a professora de Geografia e História, que faríamos um convite aos familiares para auxiliarem-nos na oficina de pipas e, aproveitaríamos o momento para ouvirmos seus relatos de como eram os brinquedos e brincadeiras, bem como a cidade, o bairro e a rua de sua infância.

\section{Execução das aulas}

As atividades foram transcorrendo conforme o planejado, assim como as visitas à sala de informática. Em nossa primeira visita, o jogo proposto era "Blocos" constante no programa Friv4 ${ }^{4}$ Enquanto treinava o jogo em casa, percebia as possibilidades pedagógicas do mesmo e em quanto poderia contribuir para o desenvolvimento do raciocínio lógico-matemático dos alunos.

Pude perceber que os estudantes sentiram-se fascinados e desafiados pelo jogo. Ao final dessa aula, perguntaram-me onde seria possível encontrá-lo na internet, pois aproveitariam para jogar em casa. No encontro seguinte na sala de informática, o desempenho do grupo superou minhas expectativas em relação ao avanço nas fases do jogo. Quando comentei sobre essa percepção, a maioria dos estudantes informou-me que haviam praticado o jogo em casa, ao longo da semana que precedeu a aula.

Nesse sentido, pude constatar, que os estudantes que apresentavam dificuldade de elaboração e organização do pensamento para a resolução de situações-problemas, demonstraram ter mais atitude e desejo de acertar quando manipularam os jogos digitais.

O próximo passo na sala de informática, seria a apresentação do Geoplano Virtual. Expliquei na sala de aula, o que era o instrumento, a finalidade para o qual foi elaborado, como e para que o utilizaríamos.

Permiti que o primeiro contato fosse de sondagem. Em seguida, sugeri a construção de algumas figuras geométricas elementares e, posteriormente, que construíssem desenhos empregando as figuras orientadas por mim.

As construções dos estudantes durante essas aulas foram agradavelmente surpreendentes, visto que os mesmos não se intimidaram diante de desafios, mas buscaram recursos criativos e geradores de deleite para si mesmos.

Orientei-lhes a confeccionar uma casa a partir das figuras geométricas planas elementares (círculo, retângulo, triângulo e quadrado). Em seguida disse-lhes que

\footnotetext{
${ }_{4}^{4}$ Friv (http://www.friv.com.br) é um site de jogos on line de grande variedade, incluindo jogos pedagógicos, com níveis de complexidade para faixas etárias e interesses diversos, além de funcionar com qualquer sistema operacional.
} 
confeccionassem outra casa, mas desta vez valendo-se apenas de triângulos e em seguida novas orientações, sempre explorando as figuras geométricas planas.

Na próxima aula expositiva levei o Geoplano físico, mostrei-lhes como manusear a goma/elástico para formar as diversas figuras e apresentei o conceito de unidade de área, que seria necessário para a aula seguinte na sala de informática.

No decorrer da aula seguinte, pedi-lhes que construíssem determinadas figuras com um número determinado de unidades de áreas no Geoplano virtual. Nesse momento, pela primeira vez durante a execução do planejamento, eles demonstraram ter dificuldade em executar o que lhes era solicitado. Após algumas tentativas com baixo índice de acerto, não insisti. Decidi que tentaria novas investigações com o Geoplano físico e então tentaria novamente no virtual.

Retomei o planejamento e fiz uma revisão da abordagem que estava adotando, pois, a dificuldade poderia ser na metodologia. Quando voltamos ao trabalho com o Geoplano físico e com as denominadas unidades de área, a dificuldade demonstrada anteriormente pareceu ter diminuído. Quando questionados a respeito disso, disseram-me que era mais fácil manipular a goma e colocá-la onde julgassem mais adequado, sendo que no virtual essa dificuldade é maior devido à distância existente entre a manipulação com as mãos e com o mouse.

De forma geral, os estudantes demonstraram muita perspicácia e indiscutível potencial de aprendizagem, mas constatei que dois dos estudantes, dentre os vinte e oito da turma, demonstravam ter menos contato com o computador e, por isso, concluí que a dificuldade não estava relacionada à unidade de área, mas sim à técnica de manuseio do mouse.

Quanto à utilização do recurso digital, encontramos, como vantagem, a facilidade do acesso, possibilitando a interação do estudante com as Tecnologias de Informação e Comunicação (TIC), sendo que aliados a esse fator encontram-se fatores motivacionais e cognitivos.

O trabalho com Geometria foi intercalado com o livro didático 'A conquista da Matemática' (Giovanni Júnior, 2011) que traz no capítulo terceiro uma unidade de estudos sobre Geometria no que tange à forma. Não perdemos de vista o caráter lúdico do processo de alfabetização, tendo desenvolvido jogos e brincadeiras, tal como "Coelhinho sai da toca geométrico", que vieram enriquecer o trabalho e estimular os estudantes à participação e envolvimento com as atividades propostas.

Para a brincadeira "Coelhinho sai da toca" contamos com o giz branco para desenhar figuras geométricas planas no chão. Ainda no interior da sala de aula ensinei-lhes a respeito da brincadeira e disse-lhes que seria eu a dar os primeiros comandos, mas eles também fariam isso.

Comecei dizendo-lhes: “- Coelhinho sai da toca retangular!" Isso significava que todos deveriam mudar para tocas que não tivessem essa forma. Quem não conseguisse um lugar em 
uma toca ficaria congelado na próxima rodada da brincadeira. Os estudantes divertiram-se bastante e solicitaram outros momentos para brincarem.

\section{Um professor muito especial}

No decorrer de nossas aulas, um estudante do $3^{\circ}$ ciclo com necessidades educacionais específicas, devido ao tratamento de doença mental, a esquizofrenia, esteve por vários momentos assistindo as aulas da janela da sala. Mesmo sendo convidado a entrar e participar conosco, sempre ouvimos sua recusa.

Entretanto, quando viu as construções que fazíamos a partir das figuras geométricas, ele informou-nos que sabia construir sólidos geométricos por meio de dobraduras. Solicitei a ele que ensinasse aos estudantes e da turma e a partir de sua anuência, solicitei sua liberação aos coordenadores da escola.

No dia combinado de sua participação com a turma, ele foi para a escola trajado com roupa social e ao ser questionado sobre o motivo, disse, cheio de entusiasmo, que seria professor de dobraduras naquela tarde.

Sua participação foi muito oportuna, trouxe momentos de ludicidade e aprendizado para toda a turma, além de trabalhar a autoestima do adolescente. Ao longo do ano letivo, esse estudante tornou-se uma espécie de monitor da turma, estando presente na sala por vários dias, prestando auxílio aos estudantes que demonstravam menos desenvoltura nas atividades propostas.

\section{Enfim, o dia da pipa e da família}

Finalmente o grande momento estava chegando: a oficina de confecção de pipas. Fizemos uma reunião com os familiares para explicarmos sobre o projeto e solicitarmos autorização para o evento no campo. A adesão das famílias foi maciça: 24 estudantes representados de um total de 28 , sendo que de três estudantes estiveram presentes o pai e a mãe, totalizando 27 participantes. Os bilhetes enviados às famílias foram confeccionados pelos próprios estudantes.

Quando da oficina, quatro representantes atenderam ao nosso convite para a confecção das pipas. Como já havíamos explorado a história da pipa e sua importância para as diversas épocas, passamos a trabalhar com sua forma, suas arestas, vértices e faces. Trabalhamos com figuras bidimensionais e objetos tridimensionais, o que chamou a atenção 
dos familiares presentes que disseram desconhecer tais informações, visto não ter tido tais informações quando de suas formações.

Os representantes das famílias ficaram muito surpresos com a participação dos estudantes e com seu envolvimento. Em nenhuma das ocasiões de desenvolvimento do projeto presenciamos situações de desavenças ou insatisfações entre os estudantes, os quais demonstravam cooperação, solidariedade e vivacidade.

Em todo o tempo tentei estabelecer uma interlocução com as diversas áreas de conhecimento, tentando minimizar as barreiras existentes entre os conhecimentos específicos de cada uma, demonstrando que, por meio da linguagem e do uso da tecnologia, é possível aproximar conteúdos das diversas disciplinas escolares.

\section{Avaliando o processo: considerações finais}

Como forma de avaliação da aprendizagem dos estudantes, além do trabalho de observação e registro das atividades, fiz um levantamento e coletânea de itens de avaliações sistêmicas como Provinha Brasil, PROALFA e Avalia-BH, formalizando um instrumento de avaliação que foi realizado por eles ao final da execução das atividades.

Entretanto, antes que esse instrumento fosse aplicado, os estudantes foram submetidos à segunda edição da Provinha Brasil, um instrumento de avaliação diagnóstica da alfabetização em âmbito nacional, a qual os estudantes do $2^{\circ}$ ano do Ensino Fundamental são submetidos no início do $1^{\mathrm{o}}$ semestre letivo e ao final do $2^{\circ}$.

Neste instrumento aplicado ao final do $2^{\mathrm{o}}$ semestre, constavam dois itens voltados para a identificação de figuras geométricas planas. Embora o nível de dificuldade fosse baixo, era imperativo que tais conceitos fossem trabalhados e devidamente explorados. Quando eles receberam o caderno de avaliação e constataram a presença dos dois itens de Geometria, comentaram sobre a facilidade de acertar a questão, já que sabiam bem a respeito do que estava sendo pedido, afirmando que aquelas questões nenhum deles erraria mais. E de fato, todos os estudantes da turma acertaram as questões, o que foi motivo de muita alegria.

Em suas avaliações, os estudantes demonstraram que os conhecimentos não são estanques e podem ser conectados às suas vivências; e, por mais simples que fosse a atividade lúdica, eles sempre elogiavam e pediam que novas atividades com a mesma proposta fossem realizadas. Kishimoto (1994) destaca a importância dessa aproximação ao afirmar que:

O jogo como promotor da aprendizagem e do desenvolvimento passa a ser considerado nas práticas escolares como importante aliado para o ensino, já que coloca o aluno diante de situações lúdicas, como o jogo, pode ser uma boa estratégia para aproximá-lo dos conteúdos culturais a serem veiculados na escola. (KISHIMOTO, 1994, p.13). 
Por isso, reforçar a relevância do papel docente é encontrar apoio em António Nóvoa (2008), que afirma caber ao professor saber organizar-se e saber organizar o trabalho escolar e profissional, diante da necessidade de repensá-lo na direção das práticas e de meios de avaliação das escolas e dos docentes.

De forma conclusiva, a aprendizagem da Matemática pode ser muito prazerosa e profícua, mas urge que repensemos nossas metodologias e abordagens, visto que os estudantes estão sempre abertos a situações estimulantes e desafiadoras, promotoras de aprendizagens significativas.

\section{Referências}

AUSUBEL, D. P. A aprendizagem significativa: a teoria de David Ausubel. São Paulo: Moraes, 1982.

Batista, A. A. G. Capacidades da alfabetização / Antônio Augusto Gomes Batista et al. _ Belo Horizonte: Ceale/FaE/UFMG, 2005. 96 p._(Coleção Instrumentos da Alfabetização; 2)

BELO HORIZONTE. Secretaria Municipal de Educação. Proposições Curriculares Ensino Fundamental Matemática. Belo Horizonte: SMED/RME-BH, 2010.

. Secretaria Municipal de Educação. Proposições Curriculares Ensino Fundamental Língua Portuguesa. Belo Horizonte: SMED/RME-BH, 2010.

BRASIL. Ministério da Educação. Secretaria de Educação Básica. Pacto Nacional pela Alfabetização na Idade Certa: Geometria. Brasília: MEC, SEB, 2014.

BRASIL. Ministério da Educação e do Desporto. Secretaria de Educação Fundamental. Parâmetros Curriculares Nacionais: Matemática, v.3. Brasília: SEF, 1998.

CAGLIARI, L. C. Alfabetizando sem o Bá- bé- bi- bó- bu. São Paulo: Scipione, 1999.

CARLOS, José. Geoplano virtual. Disponível em: http://profjosecarlos.no.comunidades.net/geoplano-virtual. Acesso em 25agosto 2016.

DANYLUK, O. S. Alfabetização Matemática: o cotidiano da vida escolar. $2^{\text {a }}$ edição. Caxias do Sul: EDUCS, 1991.

DOLZ, J.; NOVERRAZ, M.; SCHNEUWLY, B. Sequências didáticas para o oral e a escrita: apresentação de um procedimento. In: DOLZ, Joaquim; SCHNEUWLY, Bernard et al. Gêneros orais e escritos na escola. Tradução e organização de Roxane Rojo e Glaís Sales Cordeiro. Campinas, SP: Mercado das Letras, 2004. 
FRIV games: jogos online. Disponível em: http://www.frivjogosonline.com.br. Acesso em 25 de agosto 2016.

GIOVANNI JÚNIOR, JOSÉ RUY. A conquista da Matemática: alfabetização Matemática, $2^{0}$ ano. $1^{\text {a }}$ edição. São Paulo: FTD, 2011.

KISHIMOTO, T. M. O Jogo e a educação infantil. São Paulo: Pioneira, 1994.

KRAMER, S. Alfabetização, leitura e escrita-formação de professores em curso. São Paulo: Ática, 2010.

LUCCADO, M. Você é meu. São Paulo, SP: Hagnos, 2004.

NÓVOA, A. Os professores e o novo espaço público da educação. In: TARDIFF, Maurice; LESSARD, Claude. (Org.) O oficio do professor: histórias, perspectivas e desafios internacionais. Petrópolis: Editora Vozes, 2008.

SETTE, P. F. A aula de matemática no projeto UCA: O GeoGebra e o Teorema de Pitágoras. 214 f. 2013. Dissertação (Mestrado em Educação Matemática). Universidade Federal de Ouro Preto. Ouro Preto, 2013.

SMOLE, K. S.; DINIZ, M. I.; CÂNDIDO, P. Cadernos do Mathema: jogos de matemática- $1^{\text {o }}$ ao $5^{\mathrm{o}}$ ano, v.1. Editora Artmed, 2008.

SOARES, M. Letramento: um tema em três gêneros. 2. ed. Belo Horizonte: Autêntica, 2003.

SOARES, E. S. Ensinar matemática: desafios e possibilidades. Belo Horizonte: Dimensão, 2010

YOKOYAMA, L. A. Os blocos. 2014. Disponível em: <http://professoresdematematica.com.br/jogos.html>. Acesso em: 5 set. 2016.

\section{Bibliografia Resumida}

Denília Andrade Teixeira dos Santos - Licenciada em Pedagogia, Mestre em Educação pela Pontifícia Universidade Católica de Minas Gerais-(PUC/MG), doutoranda em Educação pela Pontifícia Universidade Católica de Minas Gerais-(PUC/MG). Docente no Instituto Federal de Ciência e Tecnologia de Minas Gerais (IFMG)campus São João Evangelista.

Currículo Lattes: http://lattes.cnpq.br/o341556567681359

Contato: denilia.santos@ifmg.edu.br 